\title{
PERENCANAAN DAN SIMULASI SISTEM PNEUMATIK PADA MESIN PRES BRIKET BLOTHONG BERBANTUAN PERANGKAT LUNAK
}

\author{
Darto, S.T., M.T. \\ Fakultas Teknik Universitas Merdeka Malang \\ Email : dartounmer@gmail.com
}

\begin{abstract}
The use of compressed air is growing over time. Previously, only limited use pressurized air to increase the air pressure in the tires of the vehicle. Currently pneumatic design also has grown considerably so that is no longer done manually but can be done with the help of simulation software, the use of this software is faster and easier in terms of design. The end result of this research is successfully implementing a software simulation of pneumatic systems on blothong briquette press machine.
\end{abstract}

Keywords : pneumatic systems, blothong briquette press machine, compressed air

\section{PENDAHULUAN}

Dahulu manusia menggunakan udara bertekanan untuk berbagai keperluan yang tebatas seperti menambah angin ban mobil dll, sebenarnya penggunaan udara bertekanan masih dapat di kembangkan untuk berbagai keperluan seperti proses produksi misalnya gerakan mekanik yang selama ini dilakukan oleh tenaga manusia. Gerakan mekanik juga dapat di lakukan oleh komponen pneumatic seperti silinder pneumatic, motor pneumatic, robot pneumatic dll. Perpaduan gerakan mekanik oleh akuator pneumatic dapat di padu menjadi gerakan mekanik untuk keperluan proses produksi yang terus menerus continue dan flexible.

1. Untuk mendalami penggunaan, dan cara kerja system otomasi pneumatic.

2. Memberikan contoh aplikasi penggunaan system otomasi pneumatic secara sederhana dan secara nyata.

dibahas mengenai perancangan sistem pneumatik dengan menggunakan perangkat lunak dipilih karena penggunaannya yang luas di dalam dunia industri maupun dalam kehidupan sehari-hari

Untuk mempermudah perencanaan dan memperjelas ruang lingkup permasalahan penulis membatasi pembahasan sampai simulasi perancangan sistem pneumatik. yaitu:

Adapun tujuan dari penyusunan laporan
1. Untuk mengetahui kerja suatu sistem pneumatik dan mengetahui proses pengepresan briket

2. Mengetahui fungsi dari komponen pneumatik yang ada, baik dalam simbol yang tertera pada setiap komponen maupun dalam sistem rangkaian geraknya.

3. Mampu memahami, membuat perancangan dan perhitungan sistem pneumatik

4. Untuk menambah wawasan pengetahuan mahasiswa terhadap hal - hal yang berkaitan dengan teknologi tepat guna

Pneumatik selalu berhubungan dengan teknik penggunaan udara bertekanan baik tekanan di atas 1 atmosfir maupun tekanan di bawah 1 atmosfer (vacuum). Peneumatik merupakan ilmu pengetahuan dari semua proses mekanisme di mana udara memindahkan suatu gaya atau gerakan.persamaan dalam penggunaan tersebut ialah udara sebagai fluida kerja.

Udara di permukaan bumi ini terdiri dari campuran bermacam-macam gas, komposisi dari macam gas tersebut antara lain $78 \%$ oksigen, $21 \%$ nitrogen, $1 \%$ gas lainnya seperti karbon dioksida dll. Dalam sistem pneumatik udara difungsikan sebagai media transfer dan sebagai penyimpan tenaga (daya) yaitu dengan cara di kempa atau di mampatkan. Udara termasuk golongan fluida karena sifatnya yang selalu mengalir dan bersifat compressible (mampu kempa). 
Efektifitas system gerak pneumatik memiliki batas-batas tertentu yaitu penggunaan diameter piston antara 6 sampai dengan $320 \mathrm{~mm}$, serta panjang langkah 1 sampai dengan $2000 \mathrm{~mm}$. tekanan atau tenaga yang di berikan untuk kerja pneumatic yaitu 2 sampai 15 bar dapat juga bekerja di bawah 1 atmosfer (vacuum). Selain mempertimbangkan system gerak pneumatik ada beberapa keuntungan dan kerugian yang perlu juga di pertimbangkan,antara lain:

1. Keuntungan Pneumatik

a. Fluida mudah di dapat

Udara di mana saja tersedia dengan jumlah yang tak terhingga serta udara bekas yang di hasilkan dari proses penekanan pada pneumatik dapat di buang bebas

b. Bersih dan kering

Udara mampat adalah bersih dan kering jadi apabila terjadi kebocoran pada saluran perpipaan tidak akan mengotori lingkungan sekitar pipa yang terjadi kebocoran

c. Tidak peka terhadap suhu Jadi udara yang di gunakan sepenuhnya bersih sehingga dapat di gunakan baik pada suhu tinggi mau pun suhu yang rendah,udara mampat juga dapat di gunakan pada tempat yang sangat panas

d. Aman terhadap kebakaran dan ledakan Keamanan kerja serta produksi besar dari udara mampat tidak mengandung bahaya kebakaran maupun ledakan

2. Kerugian Pneumatik

a. Gaya tekan terbatas

Udara mampat hanya dapat membangkitkan gaya yang terbatas.Untuk gaya-gaya yang besar pada suatu tekanan bisa dalam jaringan,dan di butuhkan diameter torak yang besar

b. Biaya energi tinggi

Biaya produksi udara mampat tinggi oleh karena itu untuk produksi dan distribusi di butuhkan peralatan - peralatan khusus c. Menimbulkan suara bising

Udara yang di tiup keluar menyebabkan kebisingan terutama dalam ruang-ruang kerja yang sangat mengganggu

Setelah mengetahui keuntungan kerugian dan efektifitas pneumatic selanjutnya yang perlu di ketahui dalam system pneumatic yaitu pneumatic terdiri dari rangkaian beberapa komponen antara lain:

a. Acumulator

Acumulato atau silinder kerja merupakan peralatan pneumatic yang melakukan kerja langsung.acumulator gerak linear terdiri dari beberapa jenis yaitu single acting dan double acting

b. Katup control solenoid

Katup control berfungsi untuk mengatur arah udara kempa yang akan bekerja menggerakan akuator. Katup solenoid terdiri dari beberapa jenis, pemberian nama dari setiap jenis berdasarkan pada jumlah lubang (port), jumlah posisi kerja,jenis pengerak katup dan nama tambahan lain sesuai dengan karakteristik katup.jenis katup solenoid seperti $2 / 2,3 / 2,4 / 2$, dan $5 / 2$

\section{c. Kompresor}

Kompresor berfugsi untuk membangkitkan udara bertekanan dengan cara menghisap dan memampatkan udara kemudian di simpan di dalam tangki udara sampai udara mencapai tekanan yang di perlukan.

d. Air service unit

Merupakan unit pengolehan udara bertekanan, udara kempa yang akan masuk dalam sistem pneumatik harus memenuhi persyaratan seperti tidak mengandung debu, kadar air rendah, mengandung pelumas hal ini bertujuan sebagai perawatan dari komponen pneumatic.komponen pendukung air service unit anara lain:

1. Filter udara

Berfungsi sebagai alat penyaring udara yang diambil dari udara luar yang masih banyak mengandung kotoran. Filter 
berfungsi untuk memisahkan partikelpartikel yang terbawa seperti debu dll.

2. Tangki udara

Berfungsi untuk menyimpan udara bertekanan hingga pada tekanan tertentu hingga pengisian akan berhenti, kemudian dapat digunakan sewaktu-waktu diperlukan

3. Pengering udara

Berfungsi untuk mengeringkan udara yang mengandung air agar tidak merusak komponen pneumatic

4. Tabung pelumas

Komponen sistem pneumatik memerlukan pelumasan (lubrication) agar tidak cepat aus, serta dapat mengurangi panas yang timbul akibat gesekan. Oleh karena itu udara bertekanan/mampat harus mengandung kabut pelumas yang diperoleh dari tabung pelumas pada regulator.

5. Regulator udara bertekanan

Udara yang telah memenuhi persyaratan, selanjutnya akan disalurkan sesuai dengan kebutuhan. Untuk mengatur besar kecilnya udara yang masuk, diperlukan keran udara yang terdapat pada regulator, sehingga udara yang disuplai sesuai dengan kebutuhan kerjanya

e. Konduktor dan Konektor

Konduktor dan konektor merupakan komponen yang menyalurkan udara kempa menuju komponen pendukung pneumatik sapai ke akuator sehingga menjadi satu rangkaian pneumatik.

\section{Prinsip Kerja Mesin Pres Briket}

Udara disedot oleh kompresor dan disimpan pada reservoir air (tabung udara) hingga mencapai tekanan kira-kira sekitar 6 - 9 bar. Karena bila tekanan hanya dibawah 6 bar akan menurunkan daya mekanik dari silinder kerja pneumatik dan sedangkan bila bertekanan diatas 9 bar akan berbahaya pada sistem perpipaan atau kompresor. Selanjutnya udara bertekanan itu disalurkan ke sirkuit dari pneumatik dengan pertama kali harus melewati air dryer (pengering udara) untuk menghilangkan kandungan air pada udara. Dan dilanjutkan menuju ke katup udara (shut up valve), regulator, valve dan menuju ke silinder kerja. gerakan air cylinder ini tergantung dari valve. Bila valve menyalurkan udara bertekanan menuju ke inlet dari air cylinder maka piston akan bergerak maju sedangkan bila selenoid valve menyalurkan udara bertekanan menuju ke outlet dari air cylinder maka piston akan bergerak mundur.

\section{METODOLOGI PENELITIAN}

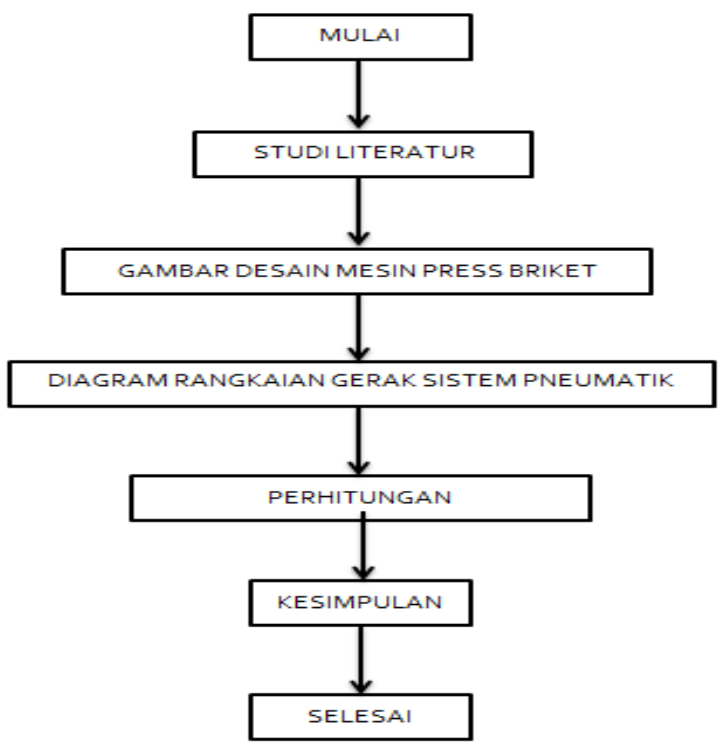

Perencanaan Dan Simulasi Sistem Pneumatik Pada Mesin Pres Briket Blothong Berbantuan Perangkat Lunak Darto, S.T., M.T. 


\section{HASIL DAN PEMBAHASAN}

Sistem Pneumatik Yang Dirancang
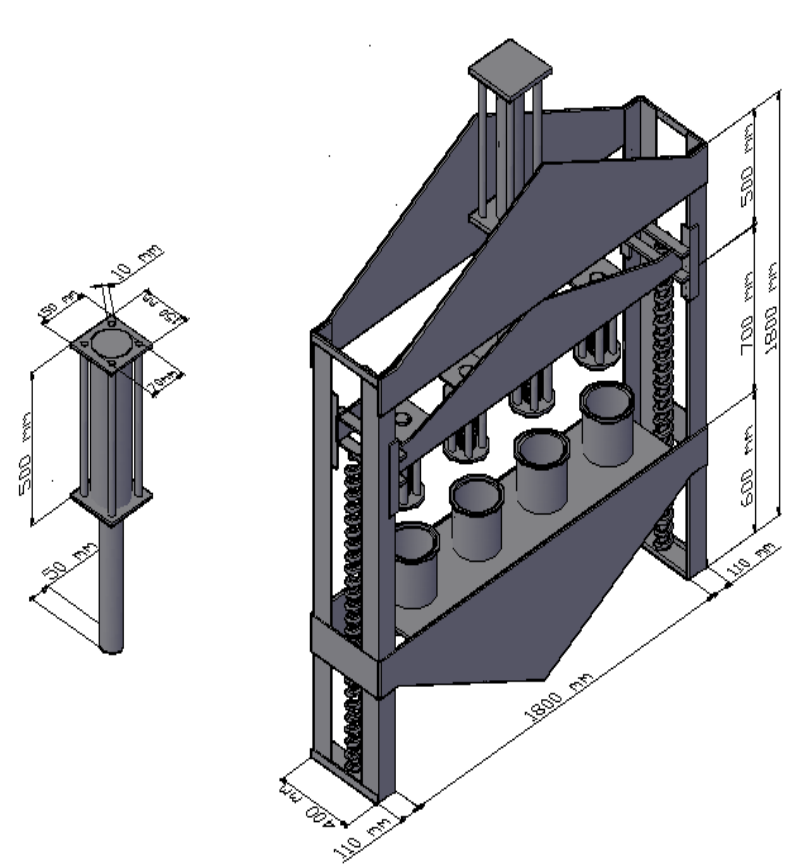

Diagram Rangkaian Sistem Pneumatik

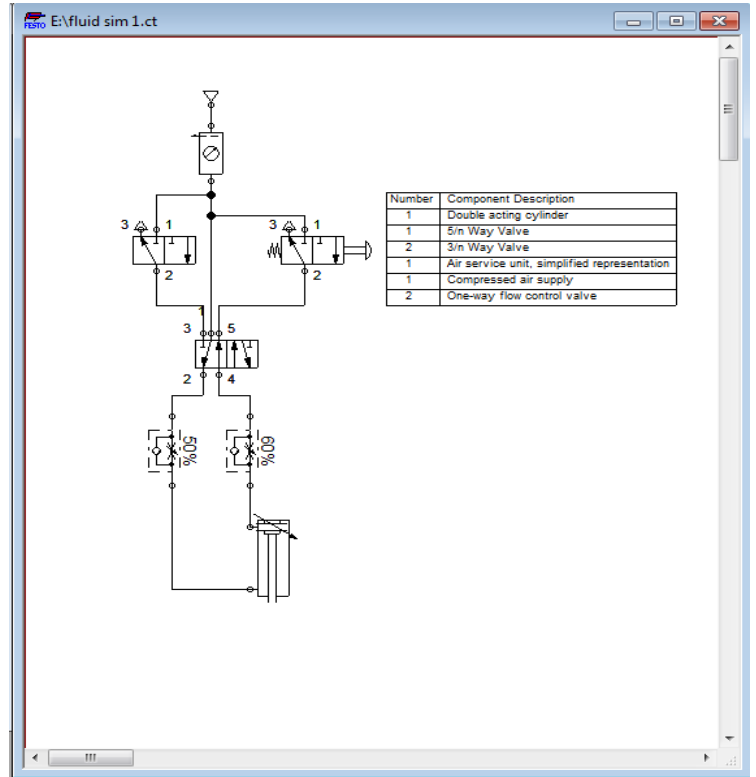

$\checkmark$ Proses Simulasi Sistem Pneumatik

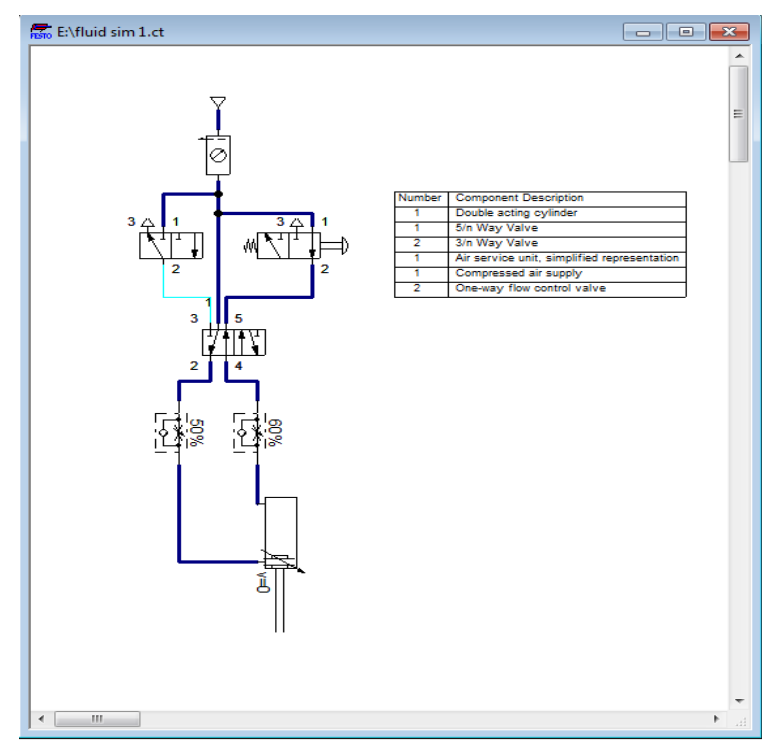

$\checkmark$ Gambar komponen pneumatic

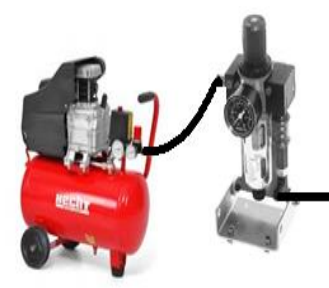

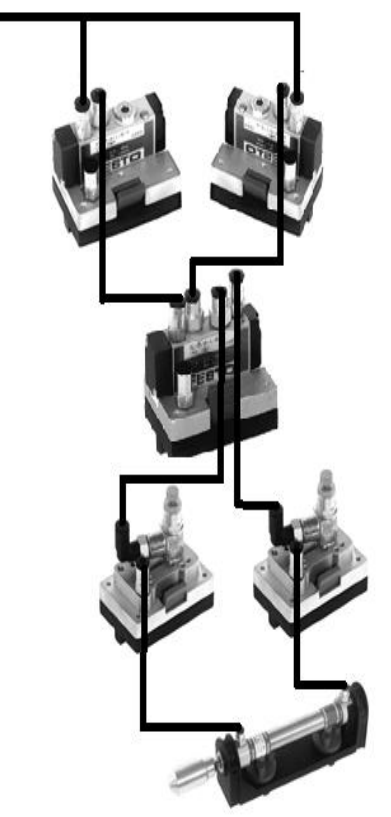




\section{Perhitungan Komponen Sistem Pneumatik}

a. Ukuran tangki udara

Di ketahui:

Kapasitas kompresor $\quad=147 \mathrm{ltr} / \mathrm{min}$

Kerugian tekanan $\quad=0,1 \mathrm{bar}$

Volume tabung kompresor $=0,16 \mathrm{~m}^{3}$

Tekanan ijin kompresor $=9$ bar

$\mathrm{V}_{\mathrm{B}}=V x\left(\frac{P_{i j i n}+P_{a t m}}{P_{a t m}}\right)$

$\mathrm{V}_{\mathrm{B}}=0,16 \mathrm{~m}^{3} \times\left(\frac{9 \text { bar }+1,01325 \text { bar }}{1,01325 \text { bar }}\right)$

$\mathrm{V}_{\mathrm{B}}=1,58 \mathrm{~m}^{3}$

b. Dimensi Silinder Pneumatik

Diketahui:

Diameter dalam piston $=70 \mathrm{~mm}$

Diameter batang piston $\quad=50 \mathrm{~mm}$

Tekanan pengukutan $=7,8$ bar

Efisiensi $=95 \%$

Suhu setelah pemampatan $=39,9^{\circ}$

$$
\begin{aligned}
\mathrm{A}_{1} & =\frac{1}{4} \times \pi \times d^{2} \\
& =\frac{1}{4} \times 3,14 \times 7^{2} \\
& =38,48 \mathrm{~cm}^{2} \\
\mathrm{~F}_{1} & =P_{e} \times A \times \eta \\
& =780000 \frac{\mathrm{m}}{\mathrm{m}^{2}} \times 0,003848 \mathrm{~m}^{2} \times 0,95 \\
& =2851,368 \mathrm{~N} \\
\mathrm{~A}_{2} & =\frac{1}{4} \times \pi \times \mathrm{d}^{2} \\
& =\frac{1}{4} \times 3,14 \times 5^{2} \\
& =19,63 \mathrm{~cm}^{2} \\
\mathrm{~F}_{2} & =P_{e} \times A \times \eta \\
& =780000 \frac{\mathrm{N}}{\mathrm{m}^{2}} \times 0,001963 \mathrm{~m}^{2} \times 0,95 \\
& =1454,583 \mathrm{~N}
\end{aligned}
$$

c. Kebutuhan udara mampat

Diketahui:

Luas penampang piston $\mathrm{A}_{1}=38,48 \mathrm{~cm}^{2}$

Luas penampang piston $\mathrm{A}_{2}=19,63 \mathrm{~cm}^{2}$

Panjang langkah piston $\quad=500 \mathrm{~mm}$

Kontak/menit $\quad=1 \mathrm{kali}$

Tekanan pengukuran $\quad=7,8 \mathrm{bar}$

Takanan udara luar

$$
\begin{aligned}
\mathrm{Q}_{\mathrm{v} 1} & =A x S \times n \times \frac{\left(P_{e} x P_{\text {atm }}\right)}{P_{\text {atm }}} \times 2 \\
& =38,48 \mathrm{~cm}^{2} \times 50 \mathrm{~cm} \cdot 1 \cdot \frac{(7,8 \text { bar } x 1 \text { bar })}{1 \text { bar }} \cdot 2 \\
& =30014,4 \mathrm{~cm}^{3} / \mathrm{min} \\
& =300,144 \mathrm{ltr} / \mathrm{min} \\
\mathrm{Q}_{\mathrm{v} 2} & =A x S \times n \times \frac{\left(P_{e} x P_{\text {atm }}\right)}{P_{\text {atm }}} \times 2 \\
& =19,63 \mathrm{~cm}^{2} .50 \mathrm{~cm} \cdot 1 \cdot \frac{(7,8 \text { bar } x 1 \text { bar })}{1 \text { bar }} .2 \\
& =15311,4 \mathrm{~cm}^{3} / \mathrm{min} \\
& =153,114 \mathrm{ltr} / \mathrm{min}
\end{aligned}
$$

d. Kecepatan gerak piston

Diketahui:

Kebutuhan udara mampat $\mathrm{Q}_{\mathrm{vl}}=300,144 \mathrm{ltr} / \mathrm{min}$ Kebutuhan udara mampat $Q_{\mathrm{v} 2}=153,114 \mathrm{ltr} / \mathrm{min}$ Luas penampang batang piston $\mathrm{A}_{1}=38,48 \mathrm{~cm}^{2}$ Luas penampang batang piston $\mathrm{A}_{2}=38,48 \mathrm{~cm}^{2}$ $\mathrm{V}_{1}=\frac{Q v}{A}$

$$
\begin{aligned}
& =\frac{0,300144}{0,003848} \frac{m^{3} / \text { menit }}{m^{2}} \\
& =78 \mathrm{~m} / \mathrm{min} \\
& =1,3 \mathrm{~m} / \mathrm{s} \\
& \mathrm{V}_{2}=\frac{Q v}{A} \\
& =\frac{0,153114}{0,001963} \frac{m^{3} / \text { menit }}{m^{2}} \\
& =78 \mathrm{~m} / \mathrm{min} \\
& =1,3 \mathrm{~m} / \mathrm{s}
\end{aligned}
$$

e. Waktu yang di butuhkan

Diketahui :

Panjang langkah piston $\quad=500 \mathrm{~mm}$

Kecepatan gerak maju piston $=78 \mathrm{~m} / \mathrm{min}$ Kecepatan gerak mundur piston $=78 \mathrm{~m} / \mathrm{min}$

$$
\begin{aligned}
& \mathrm{t}_{1} \quad=\frac{s}{v} \\
& =\frac{0,5}{1,3} \\
& =0,38 \text { detik } \\
& \mathrm{t}_{2}=\frac{s}{v} \\
& =\frac{0,5}{1,3} \\
& =0,38 \text { detik }
\end{aligned}
$$


f. Perhitungan daya kompresor

Diketahui :

Kebutuhan udara mampat $=300,144 \mathrm{ltr} / \mathrm{min}$

Tekanan pengukuran $\quad=7,8 \mathrm{bar}$

Efisiensi kerja $\quad=95$

$\mathrm{P}_{\text {output }}=\mathrm{Q}_{\mathrm{v}} \times \mathrm{P}_{\mathrm{e}}$

$=$

$0,300144 \mathrm{~m}^{3} / \min \times 780000 \mathrm{~N} / \mathrm{m}^{2}$

$=3,9 \mathrm{~kW}$

$$
\begin{aligned}
\mathrm{P}_{\text {Motor }} \quad=\frac{P_{\text {out put }}}{\eta} \\
=\frac{3,9}{0,95} \\
=4,105 \mathrm{~kW}
\end{aligned}
$$

\section{Pembahasan Hasil Perhitungan}

\section{Kapasitas Tabung Kompresor}

Kapasitas tabung kompresor dipengaruhi oleh volume dari tabung kompresor di kali tekanan absolut.Untuk tabung kompresor di sini di ketahui sebesar $0,16 \mathrm{~m}^{3}$ serta Tekanan absolut sebesar 9,68 bar didapat nilai sebesar itu dihitung menggunakan rumus di atas. Tekanan absolut di pengaruhi oleh tekanan ijin dan tekanan atmosfir. Sehingga kapasitas tabung kompresor setelah dihitung mendapatkan hasil sebesar $1,58 \mathrm{~m}^{3}$

$>$ Gaya Maju Piston

Setelah di lakukan perhitungan gaya maju piston di dapatkan hasil sebesar 2851,37 N .gaya maju piston tersebut di pengaruhi oleh luas panampang piston, tekanan pengukuran serta efisiensi. untuk efisiensi direncanakan sebesar 95\%, untuk tekanan pegukuran biasanya digunakan 2 sampai 15 bar.

$>$ Gaya Mundur Piston

Gaya mundur piston sama seperti gaya maju piston yang dipengaruhi oleh luas panampang piston, tekanan pengukuran serta efisiensi.dari hasil perhitungan didapat gaya mundur piston yaitu sebesar 1454,85 N. didapat nilai yang berbeda antara gaya maju dan mundur piston di karenakan luas penampang batang piston yang berbebeda.

\section{Kebutuhan Udara Mampat}

Kebutuhan udara mampat di sini didapatkan 2 nilai karena acuator atau silinder yang di gunakan di sini adalah double acting cylinder. Kebutuhan udara mampat pada perencanaan pneumatik dipengaruhi oleh luas penampang piston, panjang langkah piston, waktu yang dibutuhkan untuk piston menempuh panjang langkah tersebut serta tekanan absolut. Sehingga berdasarkan hasil perhitungan didapat nilai $\left(\mathrm{Q}_{\mathrm{v}}\right)$ sebesar $\mathrm{Q}_{\mathrm{v} 1}=300,144 \quad$ ltr $/ \mathrm{min} \quad$ dan $\quad \mathrm{Q}_{\mathrm{v} 2}=153,114$ $1 \mathrm{tr} / \mathrm{min}$

\section{Kecepatan Gerak Maju Piston}

Kecepatan gerak maju piston dipengaruhi oleh kebutuhan udara mampat dibagi dengan luasan, untuk menghitung kecepatan gerak maju piston di gunakan $\mathrm{Q}_{\mathrm{vl}}$ dan untuk luasan juga menggunakan $A_{1}$ sehingga dihasilkan nilai kecepatan sebesar $78 \mathrm{~m} / \mathrm{min}$.

\section{Kecepatan Gerak Mundur Piston}

Kecepatan gerak mundur piston sama dengan kecepatan gerak maju piston, bila dilihat pada data perhitungan terlihat nilai $\mathrm{Q}_{\mathrm{v} 1}$ dan $\mathrm{Q}_{\mathrm{v} 2}$ serta $\mathrm{A}_{1}$ dan $\mathrm{A}_{2}$ keduanya sebanding sehingga saat di hitung untuk mencari kecepatan gerak mundur piston $\mathrm{Q}_{\mathrm{v} 2}$ dibagi $\mathrm{A}_{2}$ maka hasilnya sama.

\section{Waktu Langkah Maju \& Mundur Piston} Untuk menghitung waktu yang di butuhkan factor yang mempengaruhi ialah panjang langkah piston dan kecepatan gerak piston,pada perhitungan sebelum nya di ketahui kecepatan gerak piston ialah sama sehingga waktu yang dibutuhkan untuk piston maju dan mundur sama yaitu sebesar 0,38 detik.

\section{Daya Luaran Pompa}

Daya luaran pompa di hitung dari kebutuhan udara mampat dikali dengan tekanan pengukuran, untuk kebutuhan udara mampat di gunakan nilai yang terbesar, sehingga 
didapat nilai daya luaran pompa sebesar 3,9 $\mathrm{kW}$

\section{Daya Motor Kompresor}

Daya motor kompresor didapat dari daya luaran pompa dibagi dengan efisiensi, sehinggan daya motor kompresor dapat diketahui sebesar 4,105 kW

\section{KESIMPULAN}

a. Telah dapat dirancang dan disimulasikan mesin press briket blothong dengan menggunakan sistem pneumatik berbantuan perangkat lunak.

b. Pengembangan alat pembuat briket dengan sistem kendali pneumatik, dapat menghasilkan waktu proses kerja yang lebih cepat dari pada alat pembuat briket manual hal ini dapat dilihat dari perhitungan langkah maju piston yang sebesar 0,38 detik.

c. Daya luaran pompa yang dibutuhkan untuk memenuhi kebutuhan udara dalam rangka menunjang kerja dari alat Pres Briket Blothong yaitu sebesar 3,9 kW

d. Daya motor kompresor yang dibutuhkan untuk menggerakkan kompresor pada alat pres briket blothong adalah $4,1 \mathrm{~kW}$

\section{REFERENSI}

[1] H. Meixner, E. Saver, 1989, Introduction to Electro-Pneumatic, Esslingen :Festo Didactic KG.

[2] Joseph J Sullivan, Hadi Podo, 1996, Kamus Ungkapan Inggris-Indonesia Dictionary of Idioms and Idiomatic Expressions, Jakarta : Gramedia Pustaka Utama.

[3] Peter Patient, Roy Pickup, Norman Powell, 1985, Pengantar Ilmu Teknik Pneumatika, Alih Bahasa Alex Tri Kantjono Widodo, Jakarta : Gramedia.

[4] Sisjono, 1997, Sistem Kontrol Nyumatik, Bandung : Departemen Pendidikan dan Kebudayaan Direktorat Jenderal Pendidikan Dasar dan Menengah Pusat Pengembangan Penataran Guru Teknologi Bandung.

[5] , 1999, Pneumatik dan Hidrolik Lanjut, Bandung : Departemen Pendidikan Nasional Direktorat Pendidikan Dasar dan
Menengah Pusat Pengembangan Penataran Guru Teknologi Bandung.

[6] ___ Petrus Uty, 2001, Dasar-dasar Teknik Otomasi, Bandung : Departemen Pendidikan Nasional Direktorat Pendidikan Dasar dan Menegah Pusat Pengembangan Penataran Guru Teknologi Bandung.

[7] Sugihartono, 1992, Dasar-dasar Teknik Kontrol Pneumatik, Bandung : Divisi Pengembangan Bahan Belajar PPPG Teknologi Bandung.

[8] ___ 1995, Diagram Rangkaian Pneumatik, Bandung : Media Cetak PPPG Teknologi Bandung.

[9] S. Wojowasito, Tito Wasito W, 1980, Kamus Lengkap Inggris-Indonesia Indonesia-Inggris, Bandung : Penerbit Hasta.

[10] Suyanto, 2002, Kumpulan Modul Latihan Lewat Simulator Pneumatik Tingkat Dasar, Yogyakarta :Universitas Negeri Yogyakarta.

[11] Thomas Krist, 1993, Dasar - dasar Pneumatik, Alih Bahasa Dines Ginting, Jakarta : Erlangga.

[12] Tim Penulis, Pneumatik, Jakarta : Festo Didactic

[13] Volker von der Heide, Franz-Josef Hölken, Arbeitsbuch Steuerungstechnik Metall 